\title{
BMJ Open Development and evaluation of the OHCITIES instrument: assessing alcohol urban environments in the Heart Healthy Hoods project
}

\author{
Xisca Sureda, ${ }^{1}$ Albert Espelt, ${ }^{2,3,4,5,6}$ Joan R Villalbí, ${ }^{2,3,5,7,8}$ Alba Cebrecos, ${ }^{1,9}$ \\ Lucía Baranda, ${ }^{10}$ Jamie Pearce, ${ }^{11}$ Manuel Franco ${ }^{1,12}$
}

To cite: Sureda X, Espelt A, Villalbí JR, et al. Development and evaluation of the OHCITIES instrument: assessing alcohol urban environments in the Heart Healthy Hoods project. BMJ Open 2017;7:e017362. doi:10.1136/ bmjopen-2017-017362

- Prepublication history and additional material for this paper are available online. To view please visit the journal (http:// dx.doi.org/10.1136/bmjopen2017-017362).

Received 19 April 2017 Revised 3 August 2017 Accepted 17 August 2017

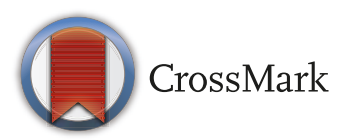

For numbered affiliations see end of article.

Correspondence to and Dr Xisca Sureda; francisca.sureda@uah.es

\section{ABSTRACT}

Objectives To describe the development and test-retest reliability of OHCITIES, an instrument characterising alcohol urban environment in terms of availability, promotion and signs of consumption.

Design This study involved: (1) developing the conceptual framework for alcohol urban environment by means of literature reviewing and previous alcohol environment research experience; (2) pilot testing and redesigning the instrument; (3) instrument digitalisation; (4) instrument evaluation using test-retest reliability.

Setting Data for testing the reliability of the instrument were collected in seven census sections in Madrid in 2016 by two observers.

Primary and secondary outcome measures We computed per cent agreement and Cohen's kappa coefficients to estimate inter-rater and test-retest reliability for alcohol outlet environment measures. We calculated interclass coefficients and their $95 \%$ Cls to provide a measure of inter-rater reliability for signs of alcohol consumption measures.

Results We collected information on 92 on-premise and 24 off-premise alcohol outlets identified in the studied areas about availability, accessibility and promotion of alcohol. Most per cent-agreement values for alcohol measures in on-premise and off-premise alcohol outlets were greater than $80 \%$, and inter-rater and test-retest reliability values were generally above 0.80 . Observers identified 26 streets and 3 public squares with signs of alcohol consumption. Intraclass correlation coefficient between observers for any type of signs of alcohol consumption was $0.50(95 \% \mathrm{Cl}-0.09$ to 0.77$)$. Few items promoting alcohol unrelated to alcohol outlets were found on public spaces.

Conclusions The OHCITIES instrument is a reliable instrument to characterise alcohol urban environment. This instrument might be used to understand how alcohol environment associates with alcohol behaviours and its related health outcomes, and can help in the design and evaluation of policies to reduce the harm caused by alcohol.

\section{INTRODUCTION}

Harmful use of alcohol is one of the leading contributors to the global burden of disease,
Strengths and limitations of this study

DHCITIES instrument is, to our knowledge, the first instrument to characterise comprehensively, through direct observation and via app, alcohol urban environment including availability and accessibility, promotion and signs of alcohol consumption.

- OHCITIES instrument allows geolocating and capturing important characteristics of the alcohol environment, difficult or even impossible to describe using other methodologies.

- OHCITIES instrument can help in the design and evaluation of alcohol policy interventions.

- OHCITIES instrument would be time consuming to characterise the alcohol environment in a whole city. However, observers found the OHCITIES easy and quick to follow.

- OHCITIES instrument was designed in the cities of Madrid and Barcelona, but it may be adapted and further used in other urban environments.

and the leading contributor to premature death and disability worldwide in the 15-59 age group. ${ }^{1}$ Globally, harmful use of alcohol is responsible of $4 \%$ of all deaths. ${ }^{2}$ In recent years, there has been an increasing interest in how the characteristics of the places where people live, work and play may influence individual behaviours in relation to health. ${ }^{3-5}$ Physical and social environments have been associated with individual alcohol behaviours. ${ }^{16-9}$

Among the physical characteristics of the environment, the availability and accessibility of alcoholic drinks have been related to alcohol consumption and to its impact on health. ${ }^{10}{ }^{11}$ Higher availability and accessibility of alcohol outlets may increase consumption among local residents through three distinct pathways. First, by providing a more competitive local market, which can result in a reduction in the price of alcohol products; lower prices are closely related to 
higher consumption patterns. ${ }^{12}$ Second, more opportunities for alcohol promotion since alcohol outlets are places where alcohol beverages can be promoted offering drinks at discount prices and advertising beverage brands. ${ }^{11} 1314$ International evidence suggests that the presence of alcohol promotion in alcohol outlets may be associated with an increase in alcohol use. ${ }^{15-17}$ Third, by influencing alcohol-related local social norms, which lead to turning alcohol consumption into a more acceptable practice. The local visibility of alcohol products and its promotion, as well as people consuming alcohol in public places, normalises and encourages drinking behaviours, especially among younger populations. ${ }^{718}$

In recent years, there have been a number of studies measuring the exposure to alcohol environment using different methodological approaches. Most published work has relied on secondary databases. ${ }^{19-27}$ Some studies have also used Geographic Information Systems to perform advanced spatial analyses and mapping. ${ }^{21} 2526$ However, the use of secondary databases can be problematic because they are not validated and do not provide a comprehensive assessment of the alcohol environment including important information such as the alcohol promotion activities of retailers, or the visibility of alcohol consumption in public spaces. Subjective measures including self-reported perceptions have also been used $^{28-32}$ with the limitation of self-report or non-response bias. Only a few studies have used on-street observations to capture alcohol imagery, including alcohol advertising, and venues in the urban streetscape. ${ }^{183-35}$

There is a need for more valid and reliable measures to comprehensively assess the wide variety of alcohol-related stimuli we are exposed in our cities. The OHCITIES instrument was designed to characterise alcohol environment in the cities of Madrid and Barcelona as part of the 'Heart Healthy Hoods' study which seeks to identify environmental risk factors associated with cardiovascular outcomes in European cities (https://hhhproject. $\mathrm{eu} /)^{73637}$ and of the Plan on Drugs for the city of Barcelona. ${ }^{38}$ This instrument may be adapted and used in other cities to facilitate estimating the association between alcohol urban environment and alcohol behaviours, and to design and evaluate alcohol policy interventions. The aim of this study was to describe the development and test-retest reliability of OHCITIES, an instrument characterising alcohol urban environment in terms of availability and accessibility, promotion, and signs of consumption.

\section{METHODS \\ Development of the conceptual framework: main alcohol urban environment domains and items involved in each domain}

The coauthors constitute an interdisciplinary research team including experts on alcohol and social epidemiology (XS, AE, JRV, JP and MF), demography (LB) and geography (AC and JP). The authors had previously published a conceptual framework helping to understand how the urban environment may relate to alcohol drinking behaviours. ${ }^{7}$ To conceptualise this framework, the authors previously reviewed the literature researching social and physical characteristics in urban environments in relation to alcohol consumption. Authors conducted different research strategies including and combining search terms such as alcohol, alcohol consumption, drinking behaviors, retail, outlet, sales, point of sales, stores, availability, accessibility, density, proximity, advertising, promotion or marketing. Three main domains of the urban environment hypothesised to favour alcohol consumption were considered: (A) availability and accessibility of alcohol; (B) promotion of alcohol; and (C) signs of alcohol consumption. Authors further searched for instrument items measuring concepts related with the three alcohol domains. The authors used peer-reviewed studies, existing on-street tools to characterise alcohol environment and published reports that had already been reviewed to conceptualise the conceptual framework. Finally, authors also conducted field visits to observe alcohol-related characteristics in the physical environment, followed by research team deliberation and expert consultation. All of the authors reviewed the inventory of items included evaluating that they were relevant and useful for characterising alcohol environment.

Availability and accessibility of alcohol included the presence and types of locations where people purchase (off-premises) or consume (on-premises) alcohol, the geolocation and addresses of the outlets (in order to allow computing proximity and density analysis in other studies) and hours of sales. It also included activities in public spaces associated with the sales of alcohol (street vendors). Promotion of alcohol is part of the alcohol urban environment and includes advertising and sponsorship. We focused on any type of promotion associated with on-premises and off-premises that could be observed from the street, and any type of promotion in public spaces (including streets, squares, markets, and so on), beyond the outlet. Finally, we included signs of alcohol consumption in public spaces beyond on-premises as another domain that would also be part of the physical alcohol environment influencing alcohol behaviour as a measure of local norms and social acceptability.

\section{Pilot testing and redesigning of the instrument}

We pilot tested the instrument in four convenient urban neighbourhoods in Madrid and two neighbourhoods in Barcelona. Researchers chose areas they knew exposure to alcohol-related characteristics was more likely to be high to capture diverse alcohol domains and the related items for each domain, such as touristic areas. Four trained observers applied the instrument (on paper) in Madrid and Barcelona in October 2015. Data collection took place on different days of the week and different hours of the day to check the suitability of the instrument to capture the alcohol-related environment under different conditions and at various time points when alcohol behaviours are likely to vary. The results 
derived from the on-field visits allowed the research team to define and clarify conceptual definition for each alcohol domain. The researchers redesigned the instrument modifying those variables that caused discrepancies between observers, and introduced new variables previously overlooked and which were recurrently found in the assessed areas. One example of this was the variables related to alcohol promotion. In the first version of the instrument, we only included advertisements and sponsorship in showcases or visible windows associated to the outlet. Then, we realised the importance of including if each promotion was associated to an alcohol brand, price and food, or if they included alcohol images. We also realised that promotion could also be found on terraces and structural elements such as labels associated to the outlet, so we incorporated all these items.

Table 1 shows the final version of the instrument for evaluation. As the observers walked the study areas, data were collected for each of the alcohol domains at both alcohol outlets (on-premises and off-premises) and also in public space (streets, squares, and so on). In each alcohol outlet, observers collected data on the availability and accessibility-related items, and the relevant items promoting alcohol (table 1). Observers detected all items associated with alcohol outlets from the outside without entering into them. We distinguished between on-premise and off-premise alcohol outlets.

Availability and accessibility measures in alcohol outlets included on-premise and off-premise outlet types (see table 1). We recorded the presence of signs indicating the outlet's opening times and signs prohibiting the sale of alcohol products to minors. For off-premise outlets, we also registered the presence of signs banning alcohol sales after 22:00 (according to Spanish regulations).

Alcohol promotion associated to alcohol outlets included information about the presence and number of advertisements and sponsorship in showcases or visible windows. We also registered the presence and type of any furniture or structural element associated with alcohol products, and for on-premise outlets promotional items on terraces (see the items included in table 1). For each of the items, we included which type of alcohol and brand were promoted and, when applicable, if the alcohol promotion was associated with price and food, and if they contained an alcohol image.

We recorded sales and promotion of alcohol products and signs of alcohol consumption in public spaces beyond alcohol outlets. Public spaces included streets, public squares, playgrounds, parks, and any other open and green spaces.

Information of alcohol promotion in public spaces could be found on advertising billboards (standard and digital), bus shelters, kiosks, corporate vehicles or any other elements of the public realm. We distinguished between advertisement and sponsorship.

We also registered any people conducting activities on public spaces associated with the sales and promotion of alcohol such as street vendors, or promoters offering alcohol discounts.

Signs of alcohol consumption included the presence and number of bottles, cans, glasses or similar. We also gathered information of people drinking alcohol on public spaces (including the number and if they drink alone or in group).

A more detailed description of all alcohol-related main variables and items included in the instrument can be seen in table 1 .

\section{Instrument digitalisation}

The instrument was integrated in a digital application called Open Data Kit. This application enabled data collection via mobile phones (or tablets) with Android operating system (https://opendatakit.org/use/collect/). This application allows data collection, including the possibility of taking pictures and geolocating the data using GPS (Global Positioning System). The application also registers the date and time the data are collected. A more detailed description of the digital application and the integration of the instrument can be found in supplementary material 1 of the article.

\section{Final instrument evaluation: test-retest reliability}

Study area and sample size

Data collection for the reliability evaluation of the instrument was done in Madrid. The city of Madrid is divided into 21 districts, which, in turn, are divided into 128 neighbourhoods. These neighbourhoods are also divided in census sections, the smallest administrative area for the Spanish Census (population $=\sim 1000-1500$ per census section). We selected one census section in seven different neighbourhoods to evaluate the alcohol instrument. The selection of the census sections was based on variation in municipal registries of outlet density (outlet density of the included census sections ranked from 102 to 1812 outlets $/ \mathrm{km}^{2}$ ) to ensure that each census had a minimum of outlets for the reliability analysis and sufficient variability for these measurements.

\section{Training of the observers}

During May 2015, two different observers trained in administering the OHCITIES instrument. Both observers piloted the tool under the supervision of the lead researcher (XS) over a 5-hour period.

\section{Field visits}

Trained observers completed the OHCITIES walking along all sides of the street located within the chosen census section. The route in each census section was previously defined using a map that the observers followed the day of the data collection. During May and June 2016, the two observers completed the data collection, mostly on weekdays and between 17:00 and 20:00. The two observers completed the OHCITIES in the seven census sections simultaneously (to reduce variability in the alcohol environment over time), but starting their task at different locations (to avoid interaction between them). 


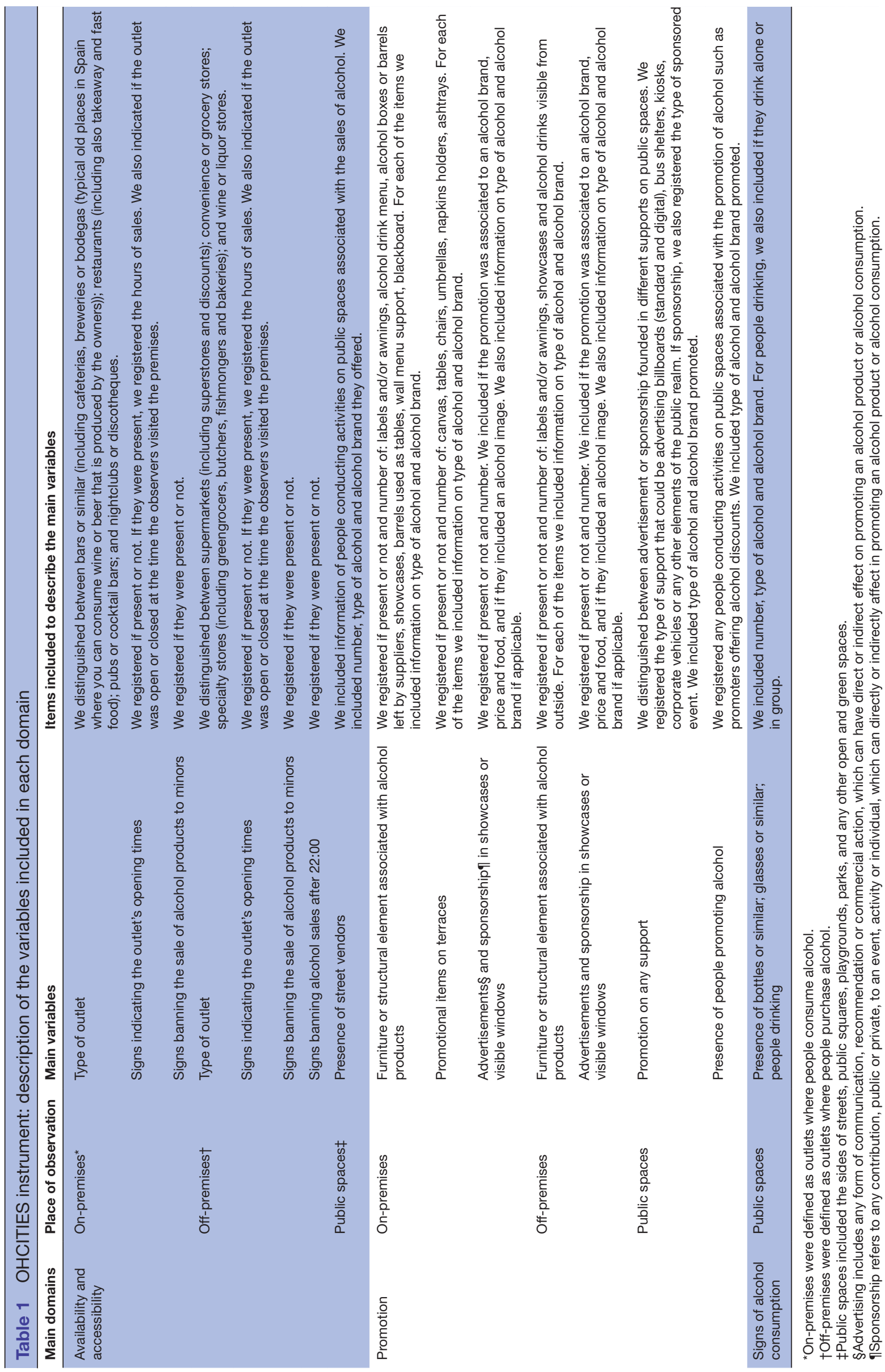


To determine intrarater reliability, one of the observers repeated the measures in one census section on consecutive days. The observer made the measurements at the same time to minimise possible variations in the alcohol environment over time. The route followed was the same as the previous day.

The data were collected without notifying or warning the owners, employees, patrons or pedestrians to avoid bias.

\section{Statistical analysis}

A descriptive analysis of the variables of interest was performed. To estimate inter-rater and test-retest reliability for alcohol outlet environment measures, we used per cent agreement and Cohen's kappa coefficients. To provide a measure of inter-rater reliability for signs of alcohol consumption measures we calculated interclass coefficients (ICCs) and their 95\% CI. The cut-off ranges used for kappa values and ICC values were as follows: $0.0-0.20$ (weak agreement), $0.21-0.40$ (poor agreement), $0.41-0.60$ (moderate agreement), 0.61-0.80 (substantial agreement) and 0.81-1.00 (almost perfect agreement) ${ }^{39}$

\section{RESULTS}

\section{Description of the sample}

Observers measured in seven census sections a total of 97 on-premise alcohol outlets of which they agreed on 92 outlets; and 28 off-premise outlets of which they agreed on 24 outlets. The number of on-premise alcohol outlets varied from 2 to 37 per census section. Among the on-premises, the observers agreed on the detection of 50 bars, 18 restaurants and 1 pub. Off-premise alcohol outlets varied between 1 and 8 per neighbourhood. Both observers detected 1 supermarket, 13 convenience or grocery stores and 4 specialty stores. There were 67 on-premises and 17 off-premises open at the time of the observations according to both observers, and $53.7 \%$ and $88.2 \%$, respectively, had some alcohol promotional item associated. There were 29 different public places (26 streets and 3 squares) where at least one of the observers found signs of alcohol consumption beyond on-premises within the seven census sections (in 17 public places both observers found signs of alcohol consumption although the total number of signs registered could varied between observers). The number of signs of alcohol consumption found in each place of observation varied between 1 and 19. Observers only reported seven items promoting alcohol (three direct ads and four sponsorships) in public spaces, and we could not compute the reliability analysis because of the insufficient sample. Observers did not find any people promoting or selling alcohol on public spaces.

Observers found the data collecting process straightforward to understand, and easy and quick to complete. Time to complete the observation in a given census section varied between 87 and $225 \mathrm{~min}$, depending on the total number of alcohol-related elements present in the census section. The mean time to complete the measures was approximately $8 \mathrm{~min}$ for alcohol outlets, and $3 \mathrm{~min}$ for alcohol promotion and signs of alcohol consumption in public spaces.

\section{Reliability for on-premise alcohol outlets}

Inter-rater and test-retest per cent agreement of alcohol environment measures in on-premises was high for all the domains and items in each domain (>80\%) (table 2). Availability and accessibility items had kappa values for inter-rater reliability of 0.67 for type of outlet; 0.72 for signs of prohibition of alcohol sales to minors; and 0.82 for signs of hours of sales. Kappa values for inter-rater reliability were generally high $(>0.80)$ for the promotion-related items. Most of the test-retest reliability values were also greater than 0.80 , and higher in almost all cases than those obtained for inter-rater reliability. Test-retest reliability values were lower for signs banning alcohol sales to minors and signs of hours of sales.

\section{Reliability for off-premise alcohol outlets}

Table 3 shows inter-rater and test-retest reliability values for off-premises. Percentage of agreement between observers was higher than $85 \%$ in almost all cases, with the exception of type of outlet $(75 \%)$ and advertisements associated to the outlet (58.82\%). Kappa values for interrater reliability for availability and accessibility items ranged from 0.49 for type of outlet to 0.77 for presence of signs of prohibition of alcohol sales to minors. Presence of advertisements (including sponsorship) associated to the outlet had low inter-rater kappa value $(0.17)$. Interrater reliability kappa values for other promotion-related items were 1.00, except for the presence of labels and/ or awnings with alcohol promotion (0.64). Test-retest per cent agreements were $100 \%$ in all cases and test-retest kappa values were all 1.00 , when they could be calculated.

\section{Reliability for signs of alcohol consumption in public spaces}

We identified 29 places (26 streets and 3 squares) with signs of alcohol consumption (table 4). The intraclass correlation coefficient for any type of signs of alcohol consumption was 0.50 (95\% CI -0.09 to 0.77 ). There was a weak or poor agreement for glasses or similar items, and people drinking. We found a moderate agreement for bottles or similar items. We could not compute testretest reliability for signs of alcohol consumption due to the characteristics of the data collected.

\section{DISCUSSION}

The results of the OHCITIES development and evaluation suggest that it is a reliable and useful instrument for characterising alcohol in urban environments.

All the items developed in each of the alcohol domains were carefully selected based on the published literature and the on-field pilot experience. Results also indicate that the instructions to the observers along with on-field training were sufficient in preparing the observers to collect high-quality and precise data. Inter-rater and 


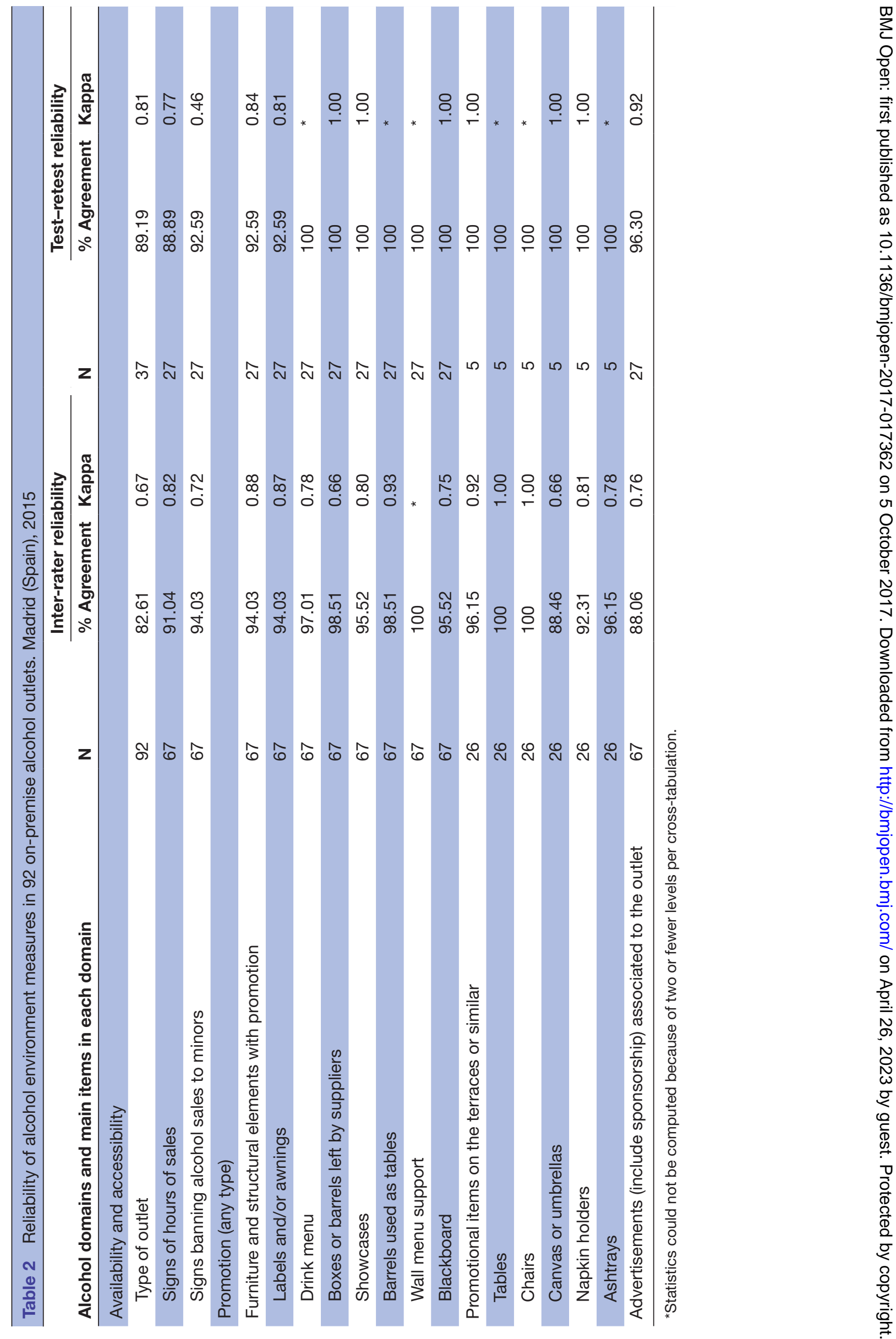


Table 3 Reliability of alcohol environment measures in 24 off-premise alcohol outlets. Madrid (Spain), 2015

\begin{tabular}{|c|c|c|c|c|c|c|}
\hline \multirow[b]{2}{*}{ Alcohol domains and main items in each domain } & \multirow[b]{2}{*}{$\mathbf{N}$} & \multicolumn{2}{|c|}{ Inter-rater reliability } & \multirow[b]{2}{*}{$\mathbf{N}$} & \multicolumn{2}{|c|}{ Test-retest reliability } \\
\hline & & $\%$ Agreement & Kappa & & $\%$ Agreement & Kappa \\
\hline \multicolumn{7}{|l|}{ Availability and accessibility } \\
\hline Type of outlet & 24 & 75.00 & 0.49 & 6 & 100 & 1.00 \\
\hline Signs of hours of sales & 17 & 88.24 & 0.76 & 5 & 100 & 1.00 \\
\hline Signs banning alcohol sales to minors & 17 & 94.12 & 0.77 & 5 & 100 & 1.00 \\
\hline Signs banning alcohol sales after 22:00 & 17 & 94.12 & 0.64 & 5 & 100 & 1.00 \\
\hline \multicolumn{7}{|l|}{ Promotion (any type) } \\
\hline Furniture and structural elements with promotion & 17 & 100 & 1.00 & 5 & 100 & * \\
\hline Labels and/or awnings & 17 & 94.12 & 0.64 & 5 & 100 & * \\
\hline Showcases & 17 & 100 & 1.00 & 5 & 100 & * \\
\hline Alcoholic drinks visible from outside & 17 & 100 & 1.00 & 5 & 100 & * \\
\hline Advertisements (include sponsorship) associated to the outlet & 17 & 58.82 & 0.17 & 5 & 100 & 1.00 \\
\hline
\end{tabular}

*Statistics could not be computed because of two or fewer levels per cross-tabulation.

test-retest reliability were high for most of the availability and accessibility measures for alcohol outlets and most of the items to characterise promotion associated to the outlets. Results showed lower reliability values between observers for type of outlet and the presence of advertisement associated to off-premises. Future research should focus on defining and training about the different types of alcohol outlets present in any particular city, as observers found difficult to assign a given category. Presence of advertising in off-premises was low, and these elements seemed less noticeable to observers and often hard to classify.

Reliability for signs of alcohol consumption was low in most cases. Some items were difficult to detect, according to the observers. Moreover, signs of alcohol consumption are subject to a temporality, and change over short time intervals. Although these variables are challenging to validate, it is important to capture them since they are part of the alcohol urban environment and can contribute to the normalisation of alcohol influencing its consumption. ${ }^{718}$

The OHCITIES was developed in the cities of Madrid and Barcelona. In these urban environments, alcohol is highly normalised and part of the eating and drinking culture. ${ }^{736}$ In Spain, $65.6 \%$ of the adult population in 2011 consumed alcohol in the past year $(77.5 \%$ of men and $54.3 \%$ of women). ${ }^{40}$ The same study showed that

Table 4 Reliability of signs of alcohol consumption found in 26 streets and 3 squares. Madrid (Spain), 2015

\begin{tabular}{llr}
\hline \multirow{2}{*}{$\begin{array}{l}\text { Signs of alcohol } \\
\text { consumption }\end{array}$} & \multicolumn{2}{l}{ Inter-rater reliability } \\
\cline { 2 - 3 } & ICC & \multicolumn{1}{c}{$\mathbf{9 5 \%} \mathbf{C l}$} \\
\hline Any type & 0.50 & -0.09 to 0.77 \\
Bottles or similar & 0.67 & 0.28 to 0.84 \\
Glasses or similar & 0.28 & -0.52 to 0.66 \\
\hline People drinking & 0.03 & -1.06 to 0.54 \\
\hline
\end{tabular}

ICC, intraclass correlation coefficient. the prevalence of binge drinking was $19.6 \%$ for men and $7.1 \%$ for women. Another study found that the prevalence of hazardous drinking among Spanish population aged 15-64 years was $6.7 \%$ for men and $3.5 \%$ for women in 2013. ${ }^{41}$ Policies regulating alcohol sales and its promotion are currently insufficient and not effective in protecting people from an excessive alcohol exposure in urban environments. The availability of alcoholic products at a relatively low cost continues to be very common. Moreover, deregulation of the retail environment favoured by European Directives has made the night-time availability of alcohol at low cost even greater, especially in large cities. ${ }^{711}$ In the same way, the promotion of alcohol is partially regulated in public spaces, with little regulation of the sponsorship of alcohol products or promotion associated to alcohol outlets, except in some local jurisdictions. ${ }^{711}$ The OHCITIES instrument may be useful to build evidence on the exposure to alcohol environments and evaluate alcohol policy implementation in different urban environments.

The goal of OHCITIES was to collect objective data of alcohol exposure in urban environments and to understand its relation with alcohol behaviours. This study is part of the 'Heart Healthy Hoods' project aiming to understand how neighbourhoods in the city of Madrid (Spain) relate with cardiovascular health of its residents. The project includes information on alcohol drinking behaviours among a cohort of adult population. We will use the OHCITIES instrument to characterise the alcohol environment in Madrid and explore how it may influence alcohol consumption reported by the local residents. The OHCITIES instrument will further be used to characterise alcohol environment in the city of Barcelona (Spain). Researchers in Barcelona will study urban alcohol environment data in its relation with alcohol drinking behaviours reported by young people and adolescents aged $12-18$ years in the city. 
The OHCITIES may also be used to evaluate policy interventions designed to change the alcohol environment and affect consumption patterns. In Europe, policies regulating alcohol sales and its promotion vary between countries, and sometimes within the same country. ${ }^{42}$ Although the instrument was designed in the cities of Madrid and Barcelona, researchers working in Edinburgh (JP) and Baltimore (MF) participate in the design and evaluation of OHCITIES instrument. This instrument could be adapted and used in other urban contexts. For example, some alcohol-related items included in the OHCITIES instrument may be modified and/or additional variables would be necessary to be developed. These modifications should be further evaluated for their reliability.

Most published literature has characterised alcohol environment using secondary databases ${ }^{19-27} 43$ and self-reported exposure to alcohol contextual factors using questionnaires. ${ }^{28-32}$ Very few studies have used on-street observation. ${ }^{183-35}$ Some of them have focused only on outdoor marketing exposure ${ }^{33}$;4 another study compared the use of Google Street View and on-street observation to characterise alcohol environment ${ }^{18}$; and another included measures of presence of alcohol outlets (including 24 hours availability of alcohol and density of alcohol outlets) and alcohol advertisements. ${ }^{35}$ OHCITIES instrument is, to our knowledge, the first instrument to characterise comprehensively, through direct observation and using digital application via mobile phones, alcohol urban environment including availability and accessibility, promotion and signs of alcohol consumption. The OHCITIES instrument will allow capturing important characteristics of the alcohol environment, which were difficult or even impossible to describe using other methodologies, and even taking pictures of them. Moreover, OHCITIES incorporates the geolocation of the data collected. This feature will enable advanced geospatial analysis and mapping all the data collected to understand how the alcohol environment and its distribution varies between areas differentiated by their socioeconomic and demographic profiles, as well as to examine how the alcohol environment influences alcohol consumption at the individual level. ${ }^{21}$ 25-27

An important challenge in future studies using OHCITIES instrument to determine how the alcohol environment relates with alcohol behaviours is to define which are the areas exerting contextual influences on the studied individuals. The area people exposed to 'alcogenic environments' would depend on the activity spaces of each individual, including where they live, study, work and play. Results derived from OHCITIES instrument could be combined with other qualitative and geographical research techniques to understand how the urban environment to which an individual is exposed may relate with alcohol attitudes and practices.

A limitation of our approach is that data collection would be time consuming to characterise the alcohol environment in a whole city. However, observers found the OHCITIES easy and quick to follow, and the instrument comprehensively describes the alcohol environment including some variables that are impossible to capture with other methodologies. Another possible limitation is the timing at which the data were collected. Almost all of the data were collected on weekdays between 17:00 and 20:00. These times were chosen to ensure that most alcohol outlets (both on-premises and off-premises) would be open during the data collection. However, at these times we were not able to capture people conducting activities on public spaces associated with the sales and promotion of alcohol (ie, street vendors, or promoters offering alcohol discounts). Perhaps data collection at other times may have captured a greater number of incidents of alcohol consumption. Future studies should conduct more measures at other times (eg, later in the evening), weekends and also in different seasons.

\section{CONCLUSIONS}

The OHCITIES instrument enables, through systematic observation, a comprehensive characterisation of alcohol urban environment in terms of availability and accessibility, promotion and signs of alcohol consumption. The OHCITIES instrument may be important in furthering our understanding of geographical differences in the alcohol environment, and how these spatial distinctions affect local normalisation and associate with alcohol behaviours. Moreover, OHCITIES can be broadly applicable to evaluate the implementation of alcohol policies and to design and support future interventions to prevent alcohol harmful use and its health-related outcomes.

Author affiliations
${ }^{1}$ Social and Cardiovascular Epidemiology Research Group, School of Medicine,
University of Alcalá, Alcalá de Henares, Madrid, Spain
${ }^{2}$ Agència de Salut Pública de Barcelona, Barcelona, Spain
${ }^{3}$ Centro de Investigación Biomédica en Red de Epidemiología y Salud Pública
(CIBERESP), Madrid, Spain
${ }^{4}$ Departament de Psicobiologia i Metodologia en Ciències de la Salut, Universitat
Autònoma de Barcelona (UAB), Cerdanyola del Vallès, Spain
${ }^{5}$ Institut d'Investigació Biomèdica Sant Pau, Barcelona, Spain
${ }^{6}$ Facultat de Ciències de la Salut de Manresa, Universitat de Vic Universitat Central
de Catalunya (UVicUCC), Manresa, Spain
${ }^{7}$ Departament de Ciències Experimentals i de la Salut, Universitat Pompeu Fabra,
Barcelona, Spain
${ }^{8}$ Grupo de Trabajo sobre Alcohol (GTOH), Sociedad Española de Epidemiología,
Barcelona, Spain
${ }^{9}$ Department of Geology, Geography and Environmental Sciences, University of
Alcalá, Alcalá de Henares, Madrid, Spain
${ }^{10}$ Research Consultant, Barcelona, Spain
${ }^{11}$ Centre for Research on Environment Society and Health, School of GeoSciences,
University of Edinburgh, Edinburgh, UK
${ }^{12}$ Department of Epidemiology, Johns Hopkins Bloomberg School of Public Health,
Baltimore, Maryland, USA

Acknowledgements The authors would like to thank Sonsoles Fuentes, Lucía Moure, Roberto Valiente and Gonzalo Ruiz for their participation in the fieldwork.

Contributors MF and XS conceived the study. XS, AE, JRV, LB and MF designed the instrument. $A C$ coded and digitised the instrument. XS and LB supervised the fieldwork. XS and AE designed and supervised the analytical procedures. XS prepared the database and analysed the data with the advice of AE and JP. XS and MF drafted the manuscript. All authors contributed substantially to the interpretation of the data and manuscript review, and approved its final version. XS and MF are the guarantors. 
Funding This study is part of the project Heart Healthy Hoods study funded by the European Research Council under the European Union's Seventh Framework Programme (FP7/2007-2013/ERC Starting Grant HeartHealthyHoods Agreement No. 336893). This study is also funded by Delegación del Gobierno para el Plan Nacional sobre Drogas (DGPNSD) (2016l047 and 2016I029). The funding sources have no involvement in the study design; in the collection, analysis or interpretation of data; in the writing of this work; or in the decision to submit the manuscript for publication.

\section{Competing interests None declared.}

Provenance and peer review Not commissioned; externally peer reviewed.

Data sharing statement There are no additional data available.

Open Access This is an Open Access article distributed in accordance with the Creative Commons Attribution Non Commercial (CC BY-NC 4.0) license, which permits others to distribute, remix, adapt, build upon this work non-commercially, and license their derivative works on different terms, provided the original work is properly cited and the use is non-commercial. See: http://creativecommons.org/ licenses/by-nc/4.0/

(c) Article author(s) (or their employer(s) unless otherwise stated in the text of the article) 2017. All rights reserved. No commercial use is permitted unless otherwise expressly granted.

\section{REFERENCES}

1. Organization WH. Global status report on alcohol and health. World Health Organization, 2014

2. Rehm J, Mathers C, Popova S, et al. Global burden of disease and injury and economic cost attributable to alcohol use and alcohol-use disorders. Lancet 2009;373:2223-33.

3. Franco M, Bilal U, Diez-Roux AV. Preventing non-communicable diseases through structural changes in urban environments. $J$ Epidemiol Community Health 2015;69:509-11.

4. Macintyre S, Ellaway A. Neighborhoods and health: an overview. Neighborhoods and health 2003:20-42.

5. Pearce J, Barnett R, Moon G. Sociospatial inequalities in healthrelated behaviours: Pathways linking place and smoking. Prog Hum Geog 2012;36:3-24.

6. Kneale J, French S. Mapping alcohol: Health, policy and the geographies of problem drinking in Britain. Drugs: Education, Prevention and Policy 2008;15:233-49.

7. Sureda X, Villalbí JR, Espelt A, et al. Living under the influence: normalisation of alcohol consumption in our cities. Gac Sanit 2017;31:66-8.

8. Sudhinaraset M, Wigglesworth C, Takeuchi DT. Social and Cultural Contexts of Alcohol Use: Influences in a Social-Ecological Framework. Alcohol Res 2016;38:35-45.

9. Organization WH. Alcohol in the European Union. Consumption, harm and policy approaches. Geneve 2012.

10. Popova S, Giesbrecht N, Bekmuradov D, et al. Hours and days of sale and density of alcohol outlets: impacts on alcohol consumption and damage: a systematic review. Alcohol Alcohol 2009;44:500-16.

11. Villalbí JR, Bosque-Prous M, Gili-Miner M, et al. [Policies to prevent the harm caused by alcohol]. Rev Esp Salud Publica 2014;88:515-28.

12. Livingston M, Chikritzhs T, Room R. Changing the density of alcohol outlets to reduce alcohol-related problems. Drug Alcohol Rev 2007;26:557-66.

13. Anderson P, de Bruijn A, Angus $\mathrm{K}$, et al. Impact of alcohol advertising and media exposure on adolescent alcohol use: a systematic review of longitudinal studies. Alcohol Alcohol 2009;44:229-43.

14. Smith LA, Foxcroft DR. The effect of alcohol advertising, marketing and portrayal on drinking behaviour in young people: systematic review of prospective cohort studies. BMC Public Health 2009;9:51.

15. Bryden A, Roberts $B$, Petticrew $M$, et al. A systematic review of the influence of community level social factors on alcohol use. Health Place 2013;21:70-85.

16. Ellickson PL, Collins RL, Hambarsoomians $\mathrm{K}$, et al. Does alcohol advertising promote adolescent drinking? Results from a longitudinal assessment. Addiction 2005;100:235-46.

17. Hurtz SQ, Henriksen L, Wang Y, et al. The relationship between exposure to alcohol advertising in stores, owning alcohol promotional items, and adolescent alcohol use. Alcohol Alcohol 2007;42:143-9.
18. Clews C, Brajkovich-Payne R, Dwight E, et al. Alcohol in urban streetscapes: a comparison of the use of Google Street View and on-street observation. BMC Public Health 2016;16:442.

19. Berke EM, Tanski SE, Demidenko E, et al. Alcohol retail density and demographic predictors of health disparities: a geographic analysis. Am J Public Health 2010;100:1967-71.

20. Chen MJ, Grube JW, Gruenewald PJ. Community alcohol outlet density and underage drinking. Addiction 2010;105:270-8.

21. Connor JL, Kypri K, Bell ML, et al. Alcohol outlet density, levels of drinking and alcohol-related harm in New Zealand: a national study. $J$ Epidemiol Community Health 2011;65:841-6.

22. Kavanagh AM, Kelly MT, Krnjacki L, et al. Access to alcohol outlets and harmful alcohol consumption: a multi-level study in Melbourne, Australia. Addiction 2011;106:1772-9.

23. Kypri K, Bell ML, Hay GC, et al. Alcohol outlet density and university student drinking: a national study. Addiction 2008;103:1131-8.

24. Pollack CE, Cubbin C, Ahn D, et al. Neighbourhood deprivation and alcohol consumption: does the availability of alcohol play a role? Int $J$ Epidemiol 2005;34:772-80.

25. Richardson EA, Hill SE, Mitchell R, et al. Is local alcohol outlet density related to alcohol-related morbidity and mortality in Scottish cities? Health Place 2015;33:172-80.

26. Shortt NK, Tisch C, Pearce J, et al. A cross-sectional analysis of the relationship between tobacco and alcohol outlet density and neighbourhood deprivation. BMC Public Health 2015;15:1014.

27. Weitzman ER, Folkman A, Folkman MP, et al. The relationship of alcohol outlet density to heavy and frequent drinking and drinkingrelated problems among college students at eight universities. Health Place 2003;9:1-6.

28. de Bruijn A, Tanghe J, de Leeuw R, et al. European longitudinal study on the relationship between adolescents' alcohol marketing exposure and alcohol use. Addiction 2016;111:1774-83.

29. Gordon R, MacKintosh AM, Moodie C. The impact of alcohol marketing on youth drinking behaviour: a two-stage cohort study. Alcohol Alcohol 2010;45:470-80.

30. Kuntsche E, Kuendig H, Gmel G. Alcohol outlet density, perceived availability and adolescent alcohol use: a multilevel structural equation model. J Epidemiol Community Health 2008;62:811-6.

31. Kuntsche EN, Kuendig H. Do school surroundings matter? Alcohol outlet density, perception of adolescent drinking in public, and adolescent alcohol use. Addict Behav 2005;30:151-8.

32. Stanley LR, Henry KL, Swaim RC. Physical, social, and perceived availabilities of alcohol and last month alcohol use in rural and small urban communities. J Youth Adolesc 2011;40:1203-14.

33. De Bruijin A, Ferreira-Borges C, Engels R, et al. Monitoring outdoor alcohol advertising in developing countries: findings of a pilot study in five African countries. Afr J Drug Alcohol Stud 2014;13:13-29.

34. Kuo M, Wechsler H, Greenberg P, et al. The marketing of alcohol to college students: the role of low prices and special promotions. Am J Prev Med 2003;25:204-11.

35. Murphy A, Roberts B, Ploubidis GB, et al. Using multi-level data to estimate the effect of an 'alcogenic' environment on hazardous alcohol consumption in the former Soviet Union. Health Place 2014;27:205-11.

36. Bilal U, Díez J, Alfayate $S$, et al. Population cardiovascular health and urban environments: the Heart Healthy Hoods exploratory study in Madrid, Spain. BMC Med Res Methodol 2016;16:104.

37. Carreño V, Franco M, Gullón P, et al. Studying city life, improving population health. Int J Epidemiol 2017;46:dyv207.

38. Brugal MT, Guitart AM, Espelt A. Pla d'Acció sobre Drogues de Barcelona 2013-16. Agència de Salut Pública de Barcelona: Barcelona, 2013.

39. Landis JR, Koch GG. The measurement of observer agreement for categorical data. Biometrics 1977;33:159-74.

40. Galán I, González MJ, Valencia-Martín JL. [Alcohol drinking patterns in Spain: a country in transition]. Rev Esp Salud Publica 2014;88:529-40.

41. Teixidó-Compañó E, Espelt A, Sordo L, et al. Differences between men and women in substance use: the role of educational level and employment status. Gac Sanit 2017

42. Bosque-Prous M, Espelt A, Guitart AM, et al. Association between stricter alcohol advertising regulations and lower hazardous drinking across European countries. Addiction 2014;109:1634-43.

43. Ayuka F, Barnett R, Pearce J. Neighbourhood availability of alcohol outlets and hazardous alcohol consumption in New Zealand. Health Place 2014;29:186-99. 